\title{
MASSACHUSETTS INSTITUTE OF TECHNOLOGY
}

LABORATORY FOR NUCLEAR SCIENCE TECHNICAL REFORT

POLARIZATION OF THE RECOIL PROTON IN THE REACTIONS

$$
Y P+\pi \rho \text { and } Y p+Y p
$$

M. Deutsch, L. Golub, P. Ki jewski, D. Pottar, M.I.T.

D. Quinn, J. Rutherfoord, Iufts Univ.

REPORT NO. COO 3069-71

Reproduction in whole or in part is permitted far any purpose by the U.S. Goverment. The data and the results that are presented in this report should not otherwise be published without prior consultation with the Laboratory for Nuclear Science.

Researches herein reported have been supported by the Atomic Energy Commission through AEC Contract AT(11-1)3069.

This Technical Report is Number 92 in a series of Technical Reports issued by the Laboratory for Nuclear science since lis inception.

\section{MASTER}

\section{NOTICE}

This repoti was peepared an an accounl of work toonumed by the Uniled states Gouternment. Meilher th: United Stoles nor the United States Atomic Entrgy Commbaion. nor any of their employets, nat any af lhel tontractora, aubconirestors, or theit emplayese, nokes bay warraty, axpesss or implied, or woumes bay logel lisbility of rasponsibulily for the accurscy, com. pleteness or usetulness of any Information, apparatus, producl or pracess duscloged, ar represenis that ils use woud not infringe prlyately owned rughts.

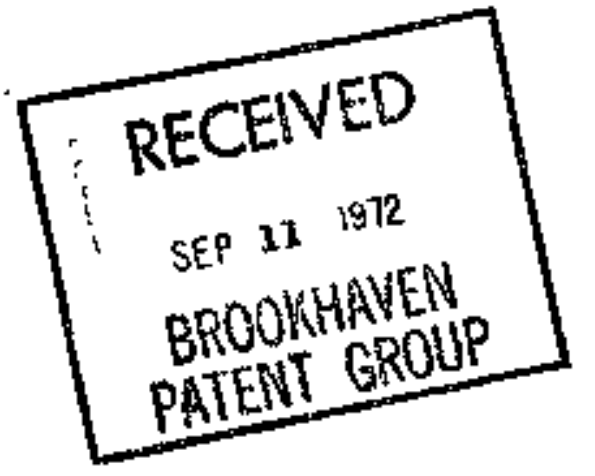

AISTRABUTIOS OF THAS DOEUGEHT IS UALL:NITED 


\section{DISCLAIMER}

This report was prepared as an account of work sponsored by an agency of the United States Government. Neither the United States Government nor any agency Thereot, nor any of their employees, makes any warranty, express or implied, or assumes any legal liability or responsibility for the accuracy, completeness, or usefulness of any information, apparatus, product, or process disclosed, or represents that its use would not infringe privately owned rights. Reference herein to any specific commercial product, process, or service by trade name, trademark, manufacturer, or otherwise does not necessarily constitute or imply its endorsement, recommendation, or favoring by the United States Government or any agency thereof. The views and opinions of authors expressed herein do not necessarlly state or reflect those of the United States Government or any agency thereof. 


\section{DISCLAIMER}

Portions of this document may be illegible in electronic image products. Images are produced from the best available original document. 
TABLE OF CONTENTS

$\begin{array}{ll}\text { ABSTRACT } & 1\end{array}$

1. Introduction 2

11. Theory 4

III. Experimental thethod 8

IV. Reconstruction of Events i3

A. General 13

B. Aligment of Proton Chambers 14

c. Measurement of the 5catter Angle 16

v. Selection of Events 20

VI. Analysis 24

A. Maximun Likelihood Method 24

B. Analyzing Power 26

C. Asymmetries 31

D. Results 35

$\begin{array}{ll}\text { REFERENCES } & 38\end{array}$

ACKNONLEDGEMENTS $\quad 39$ 
POLARIZATION OF THE RECOIL PROTON IN THE REACTIONS $Y+p \rightarrow D_{P}^{O}$ ANO $Y+P+Y+D$.

M. Doutsch, L. Golub, P. Ki jewskt, D. Potter, M.1,T. D. Quinn, J. Rutherfoord, Tutts Univ.

\section{ABSTRACT}

We have measured the polarization of the recoil proton in the reaction $Y+\rho+\pi^{\circ} \rho$. We cover the range $t=-.2(\mathrm{GeV} / \mathrm{c})^{2}$ to $t=-.65(\mathrm{GeV} / \mathrm{c})^{2}$ with a Bremsstrahlung beam that extends from $3 \mathrm{GeV}$ to $7 \mathrm{GeV}$. We detect showers from the $\pi^{\circ}$ decay with a lead converter, scintillation counter hodoscope, and lead glass counter. Protons are detected by means of counters and wire spark chambers. A sandwith of 10 carbon plates and wire chambers serves as an analyzer. We have selected $8800 n^{\circ}$ events from a sample of $1.2 .10^{6}$ triggers. The polarization is 0 at $t=-.2(\mathrm{GeV} / \mathrm{c})^{2}$ and decreases to -1 at $t=-.45(\mathrm{GeV} / \mathrm{c})^{2}$. Since the farget asymetry is expected to be about the same as the recoil proton polarization, our results can be compared with a target asymetry measurement done at Daresbury.

We have also examined the polarization of the proton in the reaction $Y+p \rightarrow Y+p$ aver the same $t$ range. With a total of 3200 events we tind the average polarization is .12 \pm .06 . 


\section{INTRODUCTION}

A substantial amount of theoretical work has been done to understand the reaction $\gamma+p \rightarrow \pi^{\circ}+p$. In partictiar Regge exchange models have been used to make detailed predictions. Measurements of the spin correlations in $y+p+\pi^{\circ} p$ serve as good test for the theories yellding such predictions.

There are three difterent experiments on spin correlations that have been done at the present time. They involve polarized ptotons with an unpolarized target, unpolarized photons with o polarized target, or polarized recoll protons with unpolarized ohotons and target. Double spin correlated experiments hove not yet been attempted. Experiments with polarized photons have been done at CEA and at SLAC'. They obtain the result that $A_{Y}=\left(o_{2}-o_{n}\right) /\left(o_{4}+o_{11}\right)$ is approximately equal to one. The conclusion one can dran is that the two helicityfilp amplitudes are about equal and that the two helicity-nonflip amplitudes are also about equal. A polarized target experiment has been done at Daresbury ${ }^{2}$. Such an experiment gives a measure of the relatlve magnitude and phase of the fltp and nontlip amplitudes. Since the measured asymetry is substantially greater than zero, both flip and nonflip amplitudes must be significant. We tave performed an experiment measuring the polarization of the recoil proton with a photon energy between $3 \mathrm{GeV}$ and $7 \mathrm{GeV}$. Such experiments have been done previously in the resonance regton. The information one obtains is similar to that obtained from the torget asymetry experiment. In 
fact one can show that $\left|A_{p}-P\right|<1-A_{Y}$. $A_{p}$ Is the target asymmetry; $P$ is the proton polarization. Since $A_{Y} * 1$, one has the result $A_{p} * P$. Furthermore, it Is quite difficult to construct a theory with $A_{p} \neq P$. Our result is stown in Figure 11. While the genseral trend of our data agrees with the polarized targat experiment, the difference between the two results is statistically significant. 


\section{THEORY}

There are a total of 8 amplitudes which describe the reaction $Y+D+\pi^{\circ} p$. Parity conservation reduces the number of independent amplitudes to 4 . We can define the four s-channel helicity amplltudes ${ }^{3}$ :

$\begin{array}{cccc} & \lambda_{Y} & { }_{n} & { }_{n}{ }^{\prime} \\ g_{1} & -1 & -\frac{1}{t} & \frac{1}{2} \\ g_{2} & 1 & -\frac{1}{2} & -\frac{1}{2} \\ 9_{3} & 1 & \frac{1}{2} & \frac{1}{2} \\ 9_{4} & 1 & -\frac{1}{2} & \frac{1}{2}\end{array}$

${ }^{\lambda} r \lambda_{n}, \lambda_{n}$, are the helicities of the photon, initial proton and $f i n a l$ proton respectively. Quantities measured in the laboratory can be written in terms of these amplitudes:

Differential cross sectlons:

$$
\frac{d g}{d t}\left(s-m^{2}\right)^{2}=\frac{1}{32 \pi} \sum_{i}\left|g_{i}\right|^{2}
$$

Target asymmetry:

$$
A_{p}=2 \mathrm{Im}\left(q_{l} g_{2} *-g_{3} g_{4} *\right) / \Sigma\left|g_{i}\right|^{2}
$$

Recoil proton polarization:

$$
P=2 I m\left(g, g_{3}^{*}-g_{2} g_{4}^{*}\right) / \Sigma\left|g_{1}\right|^{2}
$$

Polarized photon asymmetry:

$$
A_{Y}=2 \operatorname{Re}\left(g_{2} g_{3}^{*}+g_{4} g_{1}^{*}\right) / \Sigma\left|g_{1}\right|^{2}
$$


To check different experiments against each other one can derive an inequality between $A_{P}, A_{\gamma}$, and $P$. We can write

$$
\begin{aligned}
& g_{4}-g_{1}=b e^{i \theta} \\
& g_{2}-g_{3}=a e^{i \phi}
\end{aligned}
$$

using equation (2) in equation (1) we get:

$$
\begin{aligned}
& \left.A_{p}-P=2 a b \sin t_{\phi}-\theta\right) / \Sigma\left|g_{i}\right|^{2} \\
& i-A_{Y}=\left(a^{2}+b^{2}\right) / \Sigma_{i}\left|g_{j}\right|^{2}
\end{aligned}
$$

combining the equations(3):

$$
\begin{aligned}
\left|A_{P}-P\right| & =\left.2 a b i \sin (\phi-\theta)\left|\frac{\Sigma}{i}\right|_{i}\right|^{2} \\
& \leqslant 2 a b /\left.\left.\Sigma\right|_{i}\right|^{2} \\
& \leqslant\left(a^{2}+b^{2}\right) / \varepsilon_{i}\left|g_{\xi}\right|^{2} \\
& \leqslant 1-A_{Y} \\
\left|A_{p}-P\right| & \leqslant 1-A_{Y}
\end{aligned}
$$

From equations (2) and (3) it is easy to see that $A_{Y}=$ i implies $a v 0$ and hence $g_{2} * g_{3}$ and $g_{1} * g_{4} * g_{2}$ and $g_{3}$ are the helleitynonflip amplitudes, $g_{1}$ and $g_{4}$ are the helicity-flip amplitudes. The relative magnitude of the flip and nonflip amplitudes can be derived from the polarization of the proton. One cas show that:

$$
\left(g_{1}^{2}+g_{4}{ }^{2}\right) /\left(g_{2}{ }^{2}+g_{3}^{2}\right)>\frac{1}{p^{2}}\left(1-\left(1-p^{2}\right\}^{\frac{1}{2}}\right)^{2}
$$

if $|P|$ w 1 , then the $f l i p$ amplitudes are of the same order of magnitude as the nonflip amplitudes. 
A great deal of work has been done with Regge pole models to understand the amplitudes $g_{1}$. Because of the great variety and flexibility of the types of input going into the Theory, detailed predictions are impossible. For example, the strong cut Regge absorption model ${ }^{4}$ and the weak cut or Argonne model ${ }^{5}$ start with different sets of assumptions as input to the theory. One rather has to work backward by looking at the data and decide which features the model should contain. However, we like to point out one general result that can be derived from Regge pole theory. We write the hellcity-nonflip amplltudes in terms of the t-channel unnatural parlty exchange amplitude $w_{0}{ }^{-}\left(S^{p}=1^{-}, 1^{G}=1^{+}\right)$:

$$
w_{0}=\frac{1}{\sqrt{2}}\left(g_{2}-g_{3}\right)
$$

There is no known particle with the required quantum numbers to contribute to $\mathrm{w}_{\mathrm{o}}{ }^{-}$. Furthermore, pole-Fomeron cuts contrlbute equally to $g_{2}$ and $g_{3}$. As a result we have $g_{2}=g_{3}$ and, as demonstrated above, the target assymetry is equal to the recoil proton polarization.

For the reaction $y+p \rightarrow y+p$ we can wrtte 16 s-channel helicity amplitudes. Only 6 amplitudes are independent if we use time reversal and parity conservation:

\begin{tabular}{ccccc} 
& $\lambda_{y i}$ & $\lambda$ l & $\lambda_{y f}$ & $\lambda_{\mathrm{pf}}$ \\
\hline$f_{1}$ & 1 & 1 & 1 & 1 \\
$f_{2}$ & 1 & 1 & 1 & -1 \\
$f_{3}$ & 1 & -1 & 1 & -1 \\
$f_{4}$ & 1 & 1 & -1 & 1 \\
$f_{5}$ & 1 & 1 & -1 & -1 \\
$f_{6}$ & 1 & -1 & -1 & 1
\end{tabular}


$\lambda$ is the helicity; $i$, $f$ refers to initial and final. The polarlzatlon can be written in terms of these amplitudes:

$$
P=\frac{\left.2 I_{m}{ }^{\prime} f_{1} f_{2}^{*}+f_{3} f_{2}^{*}+f_{4} f_{5}^{*}+f_{4} f_{6}^{*}\right\rangle}{\left|f_{1}\right|^{2}+2\left|f_{2}\right|^{2}+\left|f_{3}\right|^{2}+2\left|f_{4}\right|^{2}+\left|f_{5}\right|^{2}+\left|f_{6}\right|^{2}}
$$

In the diffraction region the helictity-nont $f_{i p}$ amplitudes $f_{1}$ and $t_{3}$ are expected to be mostly imaginary and much larger than the other anplitudes. Thts allows us to write an approximate formula for the polarization:

$$
P=2 \operatorname{Re} f_{2} /\left(f_{1}{ }^{2}+f_{3}{ }^{2}\right)^{\frac{1}{2}}
$$

Thus the polarization gives us a measure of the relative magnltude of the helicity-flip amplitude and helicity-nonflip amplitude. 


\section{EXPERTMENTAL METHOO}

A brief description of the apparatus follows. A more detailed description can be found in the theses of Leon Golub (Proton Arm) ${ }^{6}$ and Douglas Potter (Shower Arm) ${ }^{7}$. A top view of the apparatus is shown in Figure 1. Bremstrahlung protons with an end point of about $7 \mathrm{GeV}$ generatad by the Corne1l synchrotron strike a hydrogen target. A shower detector Is located 250" from the target at an angle of $6.5^{\circ}$ relative to the direction of the incldent photon. Photons coming from the target are converted in two rodiation lengths of lead. The position of the conversion products is found by means of a $15^{\prime \prime} \times 15^{\prime \prime}$ scintillation hodoscope with a total of 24 counters. The energy of the shower is measured by a lead glass hodoscope with 18 elements. The arrangement of the blocks is lllustrated in Figure 2. A veto counter is used to discriminate between photons and charged partictes. An electromagnet serves the function of keeping down the counting rate in the veto counter and the gamma detector.

The proton detector is shown in figure 3. The direction of the recoil proton is measured by a series of 4 magnetostrlctive wire spark chambers at an angle of $69.5^{\circ}$ relative to the direction of the Incident photon. The first chamber, with an active ares of $5.5^{\prime \prime} \times 4^{\prime \prime}$, is $25^{\prime \prime}$ from the target. It 15 protected by two collimators and a permanent magnet to sweep out soft electrons. The proton can scatter in a total of 10 carbon plates, each about $2,5 \mathrm{~g} / \mathrm{cm}^{2}$ thick. The direction of the proton before and after the scatter is measured by a total of 12 wire spark chambers spaced $2^{n}$ spart. The active area of the largest chambers 


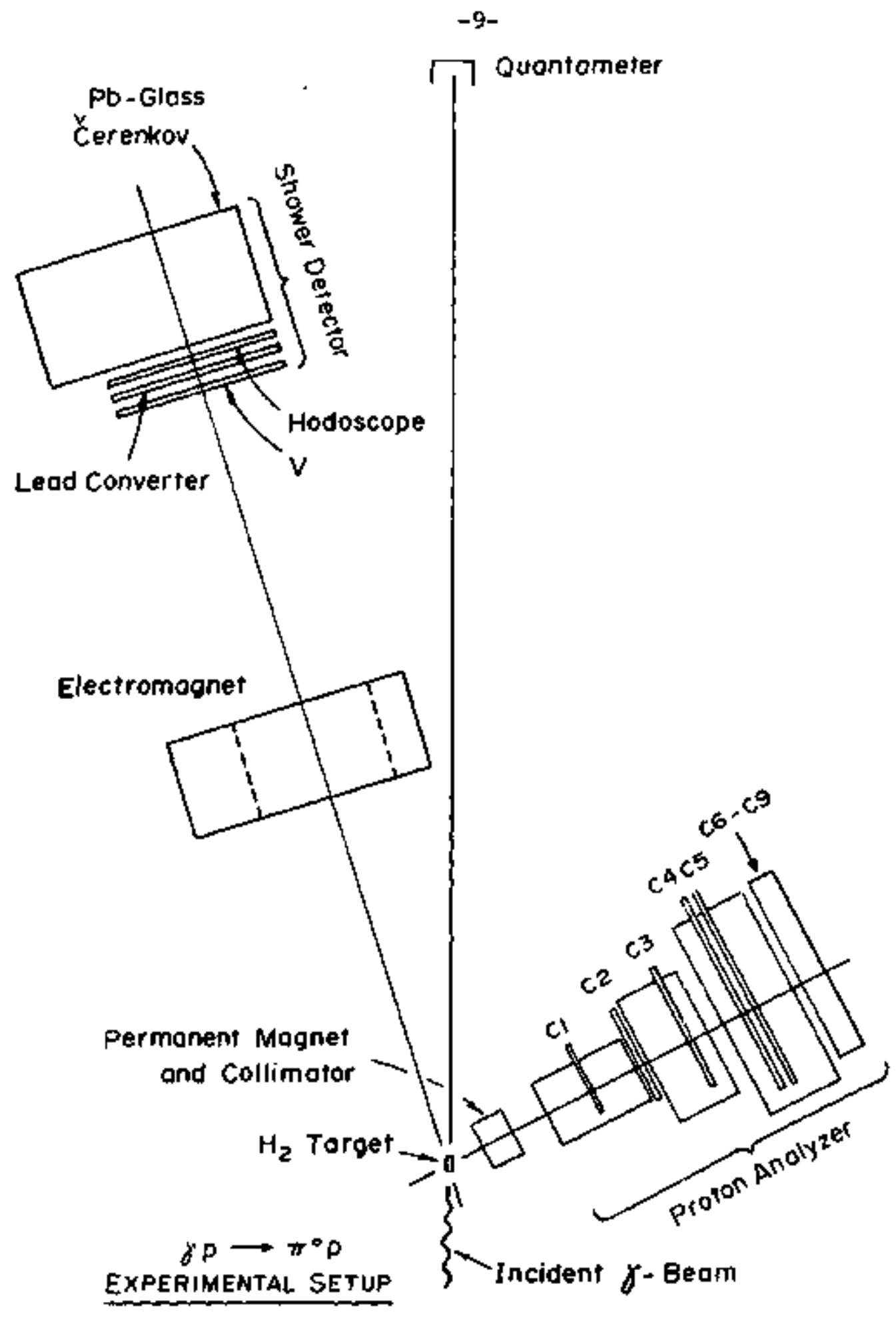

FIGURE 1. FLOOR PLAN OF EXPERIMENT 
$\frac{7}{\overline{2}}$

SHOWER ARM DETA!L

?

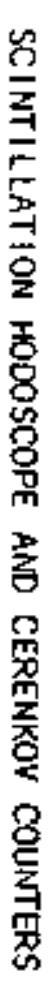

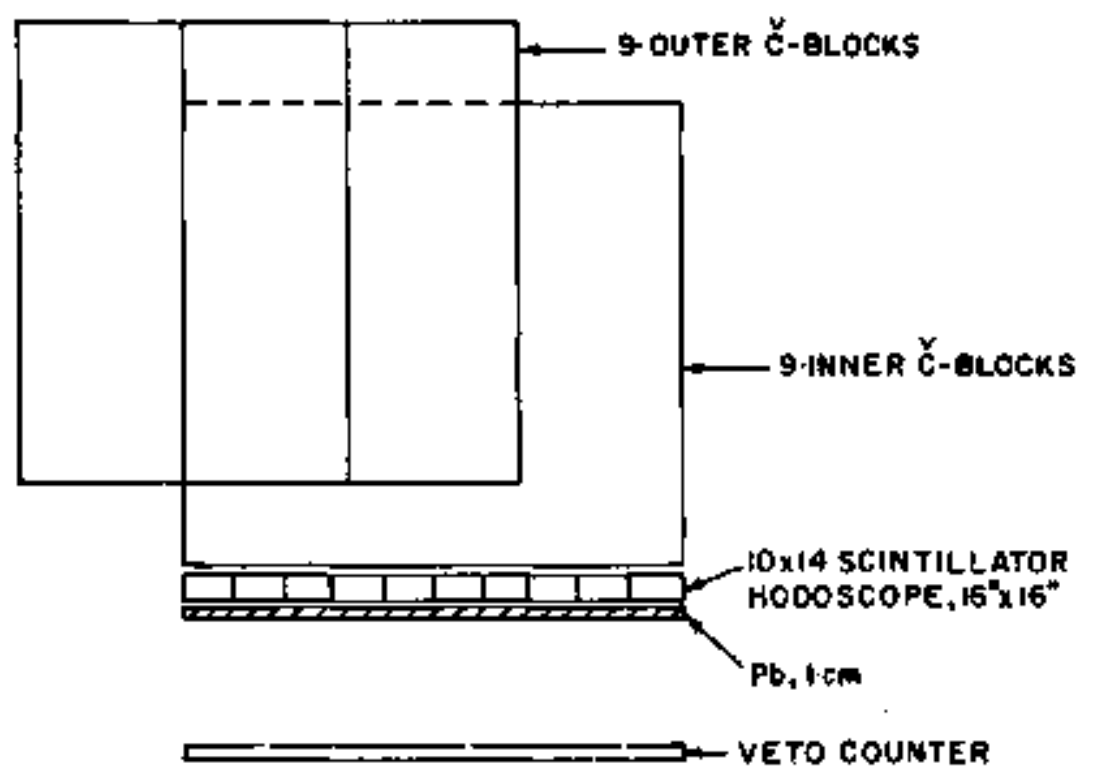

TOP VIEW

ČERENKOV ASSEMBLY
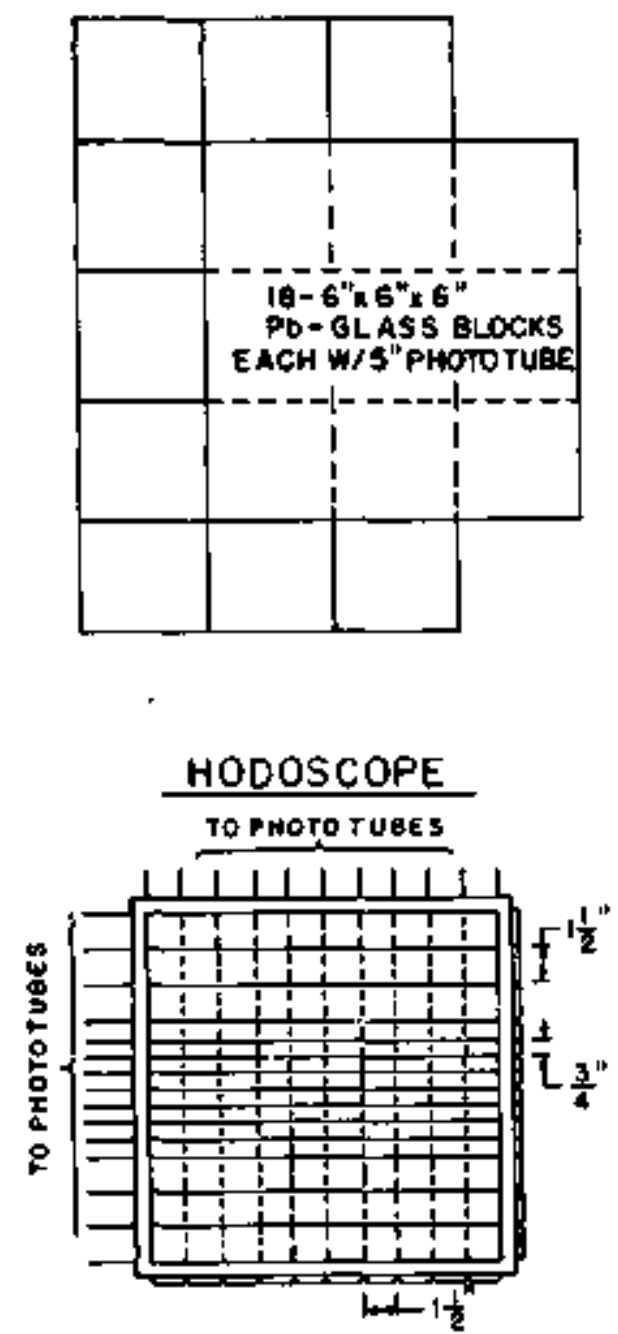

FRONT VIEWS 
PROTON ARM-DETAIL
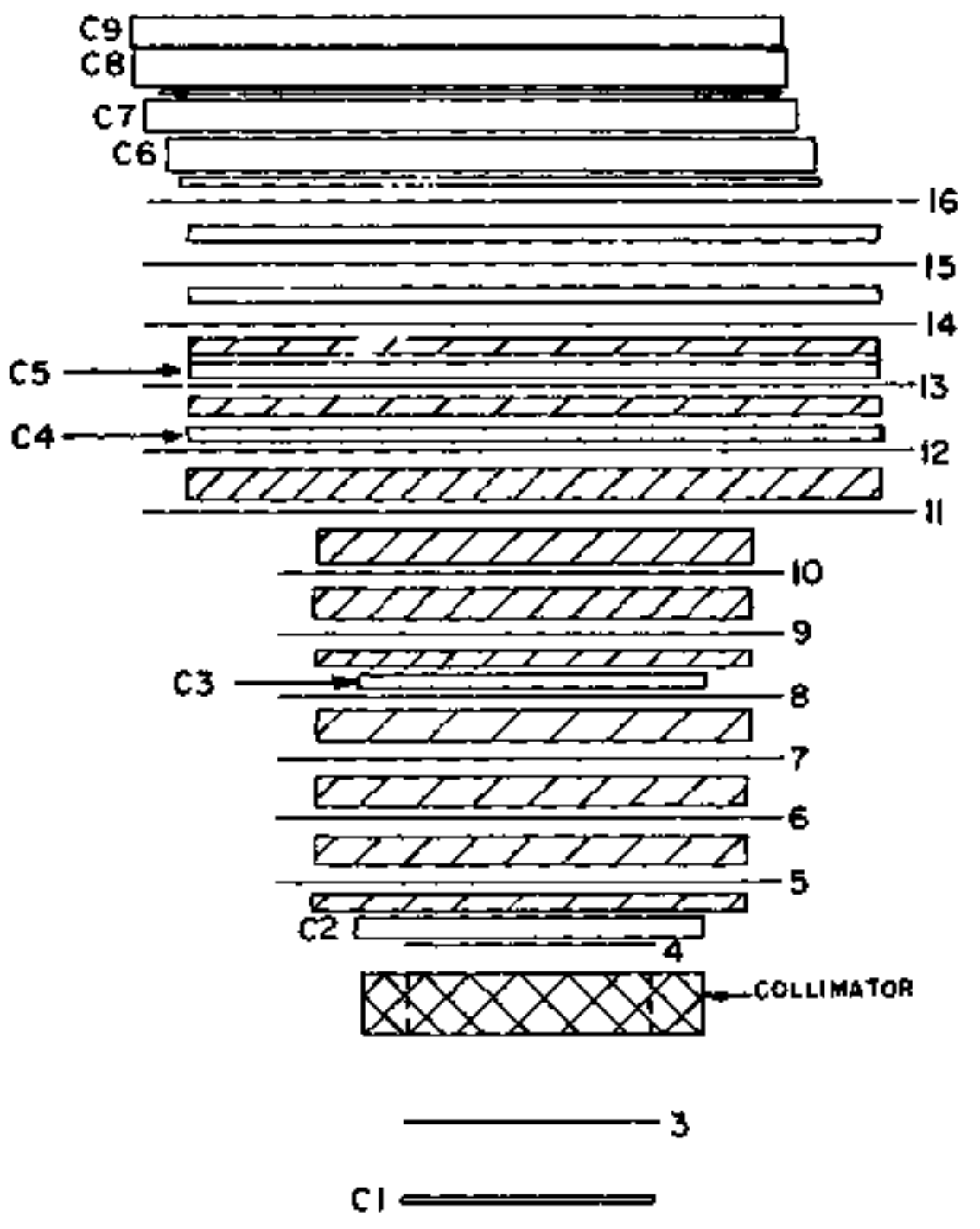

$Z Z=$ CARBON

CI

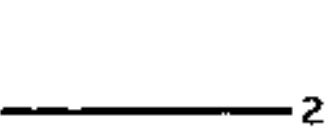

\section{X $=$ IRON}

$\square \times$ PLASTIC

- = CHAMBER

FIGURE 3. PROTON DETECTOR AND ANALYZER. 
is 23" $\times 19 "$. Interspersed in the stack of chambers are counters used for triggering and measuring $\mathrm{dE} / \mathrm{dx}$. A combination of range determl ned from the chambers and $\mathrm{dE} / \mathrm{dx}$ obtained from the counters gives us a measure of the energy of the proton. There are 4 counters beyond the stack of anelyzer chambers to extend the range of proton energies to about $350 \mathrm{MeV}$.

An event is recorded when there is a coincidence between the shower hodoscope, the leadglass blocks and the first three counters In the proton arm. The rate of triggering is as high as 2 events/ sec. All Information is process by a POPIl and stored on magnetic tape. We record the relative tImlng between counters, pulse heights from the lead glass counters and proton scintillation counters, information about which counters in the hodoscope fire, and the spark coordinates in the wire chambers. We accumulated a total of $1.2 \cdot 10^{6}$ triggers. About $3 \cdot 10^{5}$ events satisfy the requirsments of elther $Y+p+Y+p$ or $Y+p+\pi^{\circ}+p$. 


\section{REOONSTRUCTION OF EVENTS}

\section{A. General}

Reconstruction of photon tracks requires the ellmation of background sparks. We have written the necessary track following programs for the IQM $360 / 65$ and the OEC POPI. The large computer performed most of the reconstruction. The PDP! program provldes a graphic CRT dIsplay and the possibility of operator intervention. It was used for about $10^{4}$ events in which ambiguities or other difficulties were encountered, Since the spark chambers produced $90^{\circ}$ stereo Information, the track reconstruction Is performed separately In the two views. Once the appropriate sparks have been Identifled, the direction of the proton can be calculated. Extrapolating this direction Into the target gives the origin of the event.

The reconstruction of the shower direction requires a matching of information obtained from the scintillation hodoscope and the Cerenkov hodoscope. A vertical counter and a horlzontal counter in the hodoscope determines the position of a posslble shower. If this position agrees with the position of a Cerenkov block with a reasonable pulse, a shower is identifled. The position of the shower, together with the intersectlon of the proton track with the incident beam, determines the direction of the photon. The pulse helght derlved from the Cerenkov block ylelds the energy of the shower. 


\section{B. Alignment of the Proton Chambers.}

The 16 chambers constituting the proton arm of our detector were carefully aligned furing setup to get a close correspondence between measured and true coord tnates in space. Good alignment of chambers is crucial to the success of the experiment. Small displacements of the chambers can cause artificial asymetries, and hence an Incorrect polartzation measurement. A tinal adjustment of the coordinates was made by computer program. The method used is as follows. Three points which lie on a straight line sotisfy the criterion:

$$
f_{f}(x)=x_{i}-\left[\left(z_{i}-z_{i-1}\right) x_{i+1}+\left(z_{i+1}-z_{i}\right) x_{i-1}\right] /\left(z_{i+1}-z_{i-1}\right)
$$

$$
\begin{aligned}
& x_{i}=\text { coordinates in plane of chamber } \\
& z_{i}=\text { coordinate perpendicular to plane of chamber } \\
& i=\text { chamber number }
\end{aligned}
$$

During our experiment we have collected many events with unscattered proton tracks. The sparks of such tracks lie approximately on a straight IIne. If there are no corrections needed, then $f_{f}(x)$ should be Gausslan distrlbuted about zero independent of the coordinates $x_{i}$. For our experlment the wioth of the Gaussion is $.45 \mathrm{~mm}$ on the average, with the width for the ground plane somewhat smaller than the width for the high voltage plane. A standard deviation of $.45 \mathrm{~mm}$ in $f$ translates Into an error of $.37 \mathrm{~mm}$ contrlbuted by each chamber. 
Since, in fact, we do need small correctlons, we adjust the $x_{i}$ and $z_{i}$ until the average of $f_{i}(x)$ over many events is equal to zero. The most general correction consists of displacements of $x_{i}$ and $z_{i}$. and rotations about 3 mutually perpendicular axes. The only corrections we find to be necessary are displacements in $x$ and $z$ :

$$
\begin{aligned}
& x_{i}=x_{i}{ }^{\prime}+a_{i} \\
& z_{i}=z_{i}{ }^{\prime}+b_{i}
\end{aligned}
$$

using equation 2 in equation 1 we get the first order:

$$
f_{i}(x)=f_{i}\left(x^{\prime}\right)-f_{i}(a)+\frac{x^{\prime}{ }_{1+1}-x^{\prime}{ }_{i-1}}{{ }_{1+1}-\bar{z}_{i-1}^{\prime}} f_{i}(b) \quad I V-3
$$

To $f$ ind $a_{i}$ and $b_{i}$ we take events with unscattered protons and construet the sum:

$$
s_{i}=\sum_{n}\left|f_{i}(x)\right|^{2} \quad n=\text { event number }
$$

$s_{i}$ is then minimized as a function of the parameters $a_{i}=f_{i}$ (a) and $b_{1}=f_{1}(0)$. For our 16 chambers we obtain 14 numbers for each type of displacement. Each number corresponds to a particular combination of 3 adjacent chambers. We now can find $a_{i}$ by solving the 14 simultaneous equations:

$$
a_{1}=f_{i}(a)
$$

Since we have 16 unknowns we take $a_{1}=a_{2}=0$. This corresponds to fixing the absolute positan and orientation of the proton arm in space. The solution is: 


$$
a_{1}=-\sum_{n-3}^{i} \frac{z_{1}-z_{n-1}}{z_{n}-z_{n-1}} \frac{z_{n}-z_{n-2}}{z_{n-1}-z_{n-2}} a_{n-1}
$$

A similar solution obtains for $b_{i}$.

We Ilke to mentlon two important polnts about the corrections $a_{i}$. One is that they were monltored throughout the experiment. They were updated when shifts larger than $0.1 \mathrm{~mm}$ occurred in any one coordinate. The largest correction relatlve to our measured posltion was $7.5 \mathrm{~mm}$ with most corrections tess than $1 \mathrm{~mm}$. Also, the unscattered protons cover the same region in the chambers as the scattered protons near the point of scatter. It is only near the scatter point that we have to know the coordinates accurately. Sparks in regions far from the scatter point not covered by our calloration procedure are not used In calcuiating the scatter angie.

The constants b, were fixed at the beginning of the experiment and not changed thereafter. An interesting fact we find is that $z$ for the high voltage plane is different from the $z$ for the ground plane. Since our chambers vere arranged in pairs wth the high voltage planes facing each other. $z$ was displaced alternately in the positive and negative direction from the measured position. The $d i f f e r e n c e$ between $z$ (H.V) and $z$ (ground is $4 \mathrm{~mm}$ on the average.

\section{c. Measurement of the Scatter Anqle.}

In order to be able to use smait angle scatters in our andysis we need to measure the diraction of the proton before and after the scatter as accurately as possible. The accuracy of measurement 
depends on the number of sparks used in the measurement. In the case that the measurement error In the chambers dominates the error from Coulomb scattering, all available sparks give the most accurate determination of the proton direction. If on. the other hand coulomb scatterlng is more slgnificant, then only two sparks on either side of the scatter point give a best value for the proton angle. For our apparatus it turns out that at about $100 \mathrm{MteV}$ two sparks are adequate to measure the proton angle. At our highest energies of about $300 \mathrm{MeV}$ a third spark improves the error by as much as $10 \%$. More sparks give an improvement of less than 11. We have chosen the following parametrization for the proton angle:

$$
\tan \theta_{p}=\frac{x_{2}-x_{1}}{z_{2}-z_{1}}+\alpha(T)\left[\frac{x_{3}-x_{2}}{z_{3}-z_{2}}-\frac{x_{2}-x_{1}}{z_{2}-z_{1}}\right] \quad \text { iv }-6
$$

$\theta_{p}$ is the projected angle; $x, z$ are chamber coordlnates; $a(T)$ is a parameter that varies with the energy at the scatter point. For very low energies $a=0$ and the third spark does not enter into the calculation. For very high energies $a=.5$ and the third spark has maximum weight. a(T) was tound empirically by minimizlng tan $\theta$ for unscattered events. Figure 4 shows the variation of a with kinetic energy.

From the projected angles glven by equation 6 , we can find unit vectors $\hat{P}$ for the proton before the scatter and $\hat{S}$ for the proton after the scatter. The polar and azimuthal angles are: 
$-19-$
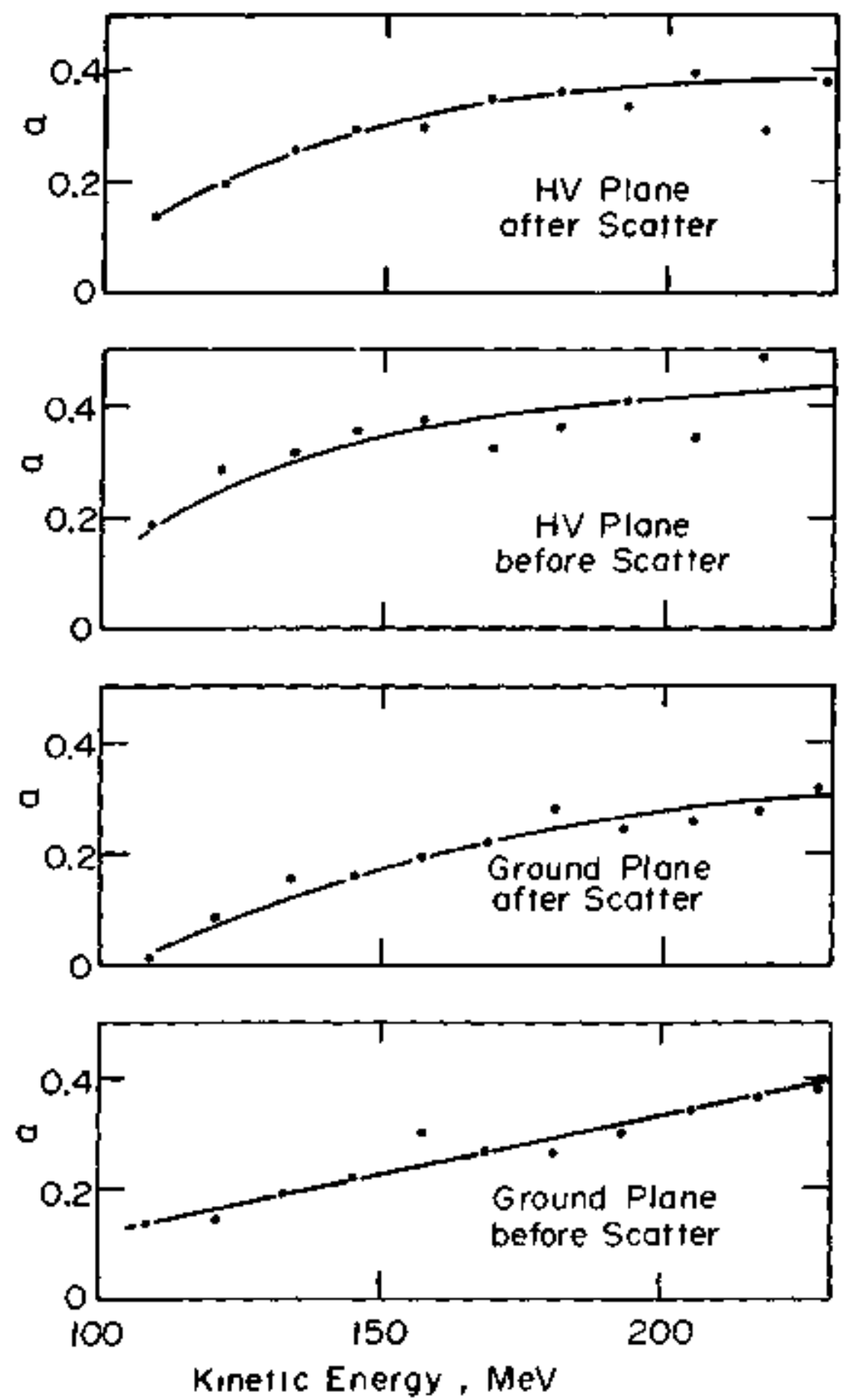

FIGURE 4. THE PARAMETER a IS THE WEIGHT ASSIGNED TO THE THIRD SPARK IN THE PROTON SCATTER ANGLE CALCULATION. 


$$
\begin{aligned}
& \tan \theta=\frac{1 \dot{S} \times \hat{P} 1}{1 \hat{S} \cdot \hat{P} I} \\
& \cos \phi=\hat{s} \times \hat{P} \cdot \hat{n} / 1 \hat{S} \times \hat{P} 1
\end{aligned}
$$

$\hat{n}$ is the normal to the reaction plane.

with the angles calculated in the above manner, we check and make sure that we have indeed a good scatter. For example, we might calculate a sizeable scatter angle for a straight track which contalns one displaced spark. To eiliminate such events we raquire colJinearity for the sparks before and after the scatter. We calculate the deviation from collinearity according to equation $\mid y-1$. All events with a deviation $\left[f(x)^{2}+f(y)^{2}\right]^{t}$ greater than $2 \mathrm{~mm}$ are rejected. We also require that the proton tracks before and after the scatter Intersect in the carbon plates to within $2 \mathrm{~mm}$. These criteria reject lof of all scatters. Of those 10 one haif are unscattered protons, while the other half are scattered protons with problems such as displaced sparks, misslng fiduclals, or double scatters. 


\section{SELECTION OF EVENTS}

of our $1.2 \cdot 10^{6}$ triggers $1.2 \cdot 10^{4}$ are suitable for a polartzation measurement. The criteria used to select the final sample are described here. About 40 of all triggers are excluded from further anslysis becsuse the pulse height recorded by two of the proton counters is too small to be consistent with even a very energetic proton. The remaining $60 \%$ are processed to identify the proton track in the wire chambers. These tracks are then exami ned by a very simple program which rejects all events with tracks that are essontially straight. The method consists of calculating a scatter angle for all carbon plates in which the proton scatter can occur. If any one angle is more than $4^{\circ}-6^{\circ}$ depending on the energy, the event is accepted. $10^{\text {s }}$ events survive this test.

Events accepted for further analysis must satisfy the following conditions. The relative timing between counters in the proton arm, and between the proton arm and the shower arm must fall inside set limits. The proton is required to originate within $3 \mathrm{~cm} \times \mathrm{gcm}$ area of the target. It must pass through an area $8.6 \mathrm{~cm} \times 5.9 \mathrm{~cm} \mathrm{43"}$ from the targot. The last two conditions assure that the proton comes from the hydrogen target and does not strike any collimators. Since track identification is done independently for the two stereo views, we require that the ranges determined from the two views agree to within one spark. On the shower arm we require that the hodoscope and Cerenkov block information is consistent and unambiguous. 
Kingmatic constroints are used to select events which sotisfy the reaction $\gamma+p+\gamma+p$ and $\gamma+p \rightarrow \pi^{\circ}+p$. From the energy of the shower $E_{Y}$, the direction of the shower $\dot{r}$, and the direction of the proton $\hat{P}$. we can calculate the kinematlc variables we need to know. For the Compton ovents we have 3 constraints on the kinematlcs. The proton has to be in the plane of the incident and recoll photon. Figure 5 is a histogram of this constraint. From $\hat{y}$ and $\hat{p}$ we can calculate $E_{y}$ and $\tau_{p}$, the kinetic energy of the proton. They can be compared with $E_{\gamma}$ determined from the Cerenkov blocks and $T_{p}$ determined from the range. For $\pi^{\circ}$ events with one shower we have a single constraint. $T_{p}$ calculated from $\hat{P}_{,}, \hat{y}$ and $E_{Y}$ can be compared with $T_{p}$ obtained from the range. The difference between the two energies has a standard deviatlon of 8 MeV. Note that this constralnt ellminates production inelastics and most inelastic proton scatters. It also rejects protons which fail to reach the end of the range because of a nuclear interactlon. Two shower events have an additional constralnt arising from the second shower.

We also check that $d E / d x$ calculated from the counter pulse helghts is consistent with the range. Figure 6 shows that the pulse height spectrum for a given energy Interval. It is evident that the use of the $d E / d x$ measurament eliminates tracks that are not protons. We can also use the pulse height to reject protons which scatter from hydrogen instead of carbon. The recoiling hydrogen nucleus adds substantially to the pulse height expected from $d \mathrm{E} / d \mathrm{x}$ alone. Hydrogen scetters are calculated to be 1.48 of our sample before we apply this criterion. Only a very small fraction are left after we apply the cut on $\mathrm{dE} / \mathrm{dx}$. 


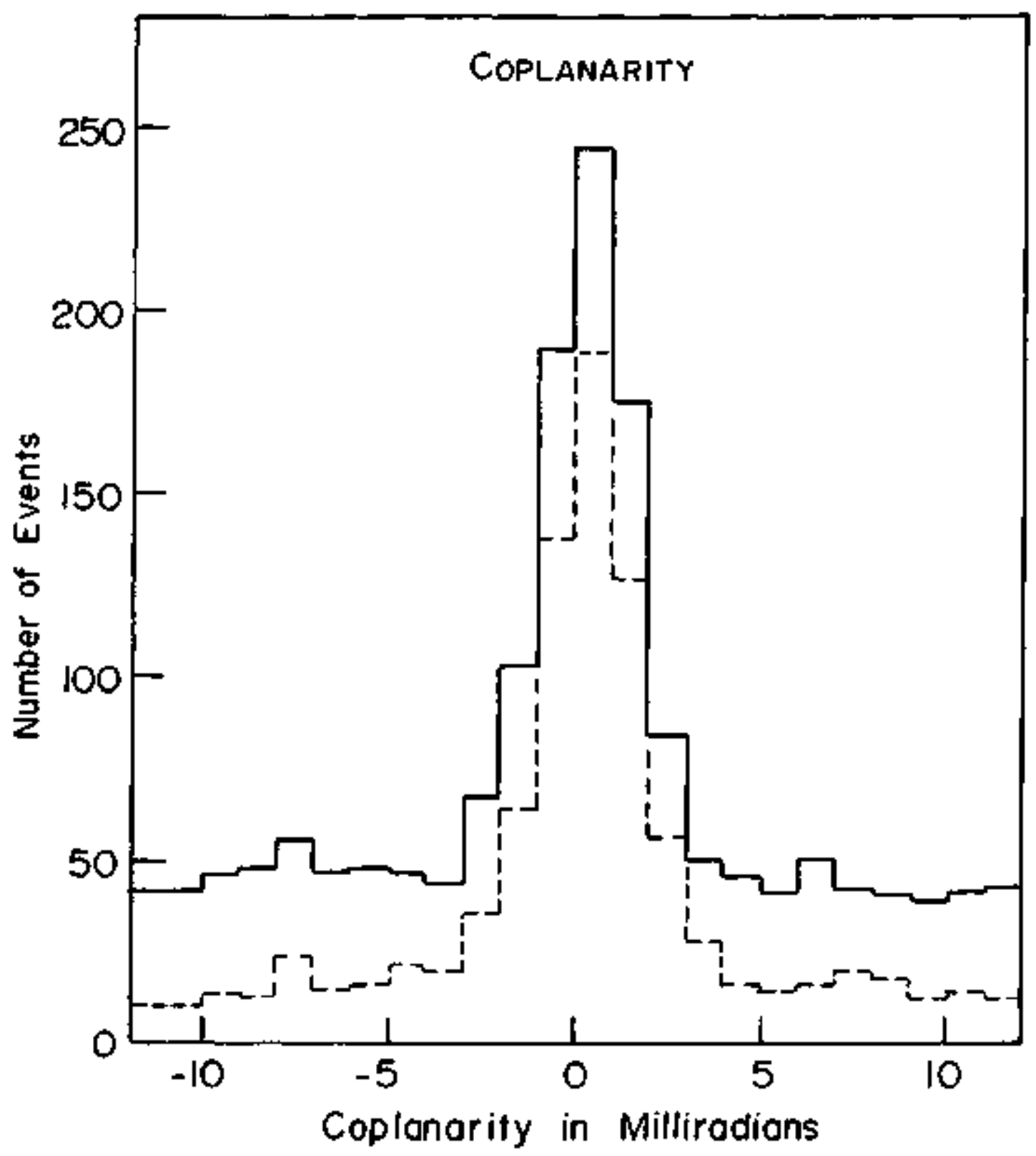

FIGURE 5. THE COPLANARITY IS DETERMINED FROM THE INCIOENT PHOTON DIRECTION, RECOIL PHOTON DIRECTION, AND THE PROTON. THE SOLID LINE \$HOWS THE UNCUT SPECTRUM: THE DOTTED LINE SHOWS THE EFFECT OF CUTS ON THE SHOWER PULSE HEIGHT ANO PROTON RANGE. 


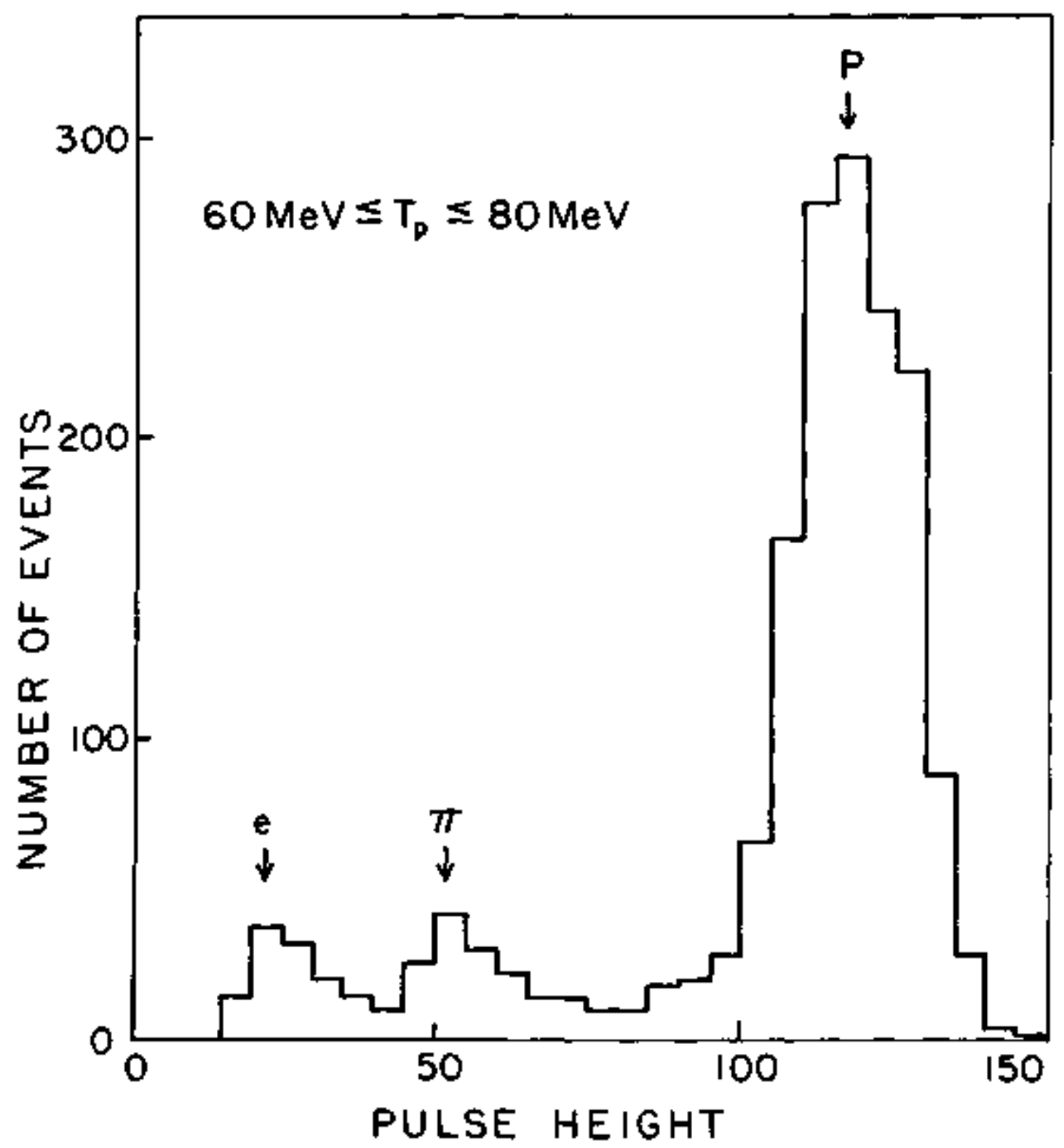

FIGURE 6. PULSE HEIGHT DISTRIEUTION OBTAINED WITH ONE OF THE PROTON COUNTERS. 
VI. ANALYSIS

\section{A. Maximum Li kel i hood Method}

To find the polarlzation from our final sample of events we have used a maximum likelihood method. The likelthood function is given by:

$$
L=\prod_{n}\left(1+B_{n} P\right)
$$

The product is over all events in a given $t b i n . B_{n}=A_{n}(\theta, T) \cos \phi$ is the analyzing power times the cosine of the azimuthal angle of the scattared praton. $P$ is the polarization. Taking alnL/ap $\leq 0$ we get the polarization:

$$
\begin{aligned}
\frac{\partial}{\partial P} \ln L & =\sum \frac{B_{n}}{1+B_{n} P} \\
0 & =\sum \frac{B_{n}}{1-B_{n}{ }^{2} P^{2}}-P \sum \frac{B_{n}{ }^{2}}{1-B_{n}{ }^{2} L} \\
P_{i} & =\sum_{n} \frac{B_{n}}{1-B_{n}{ }^{2} P_{i-1}^{2}} / \sum \frac{B_{n}^{2}}{1-B_{n}{ }^{2} P^{2} i-1}
\end{aligned}
$$

$P_{i}$ is the $i^{\text {th }}$ iteration for the polarization. If there are enough events in the sample, the likelihood function is Gaussian and the zero order solution is exact:

$$
P=\sum_{n} B_{n} / \Sigma B_{n}^{2}
$$

From $\sigma^{2}=-\frac{1}{f} \partial^{2}$ ln $L / \partial^{2} \mathrm{p}^{2}$ we get:

$$
\sigma^{2}=1 / \varepsilon B_{n}^{2}
$$


Since our Compton sample contains an admixture of $7^{\circ}$ events, the analysis is somewhat more compltated. To calculate the compton polarization we define the following quantities:

$$
\begin{aligned}
& P_{\pi}=*^{\circ} \text { polarization } \\
& P_{c} \# \text { Compton polarization } \\
& P_{m}=\text { Measured polarization } \\
& B_{n \pi}=A_{n}(\theta, T) \cos \phi \text { for } \pi^{\circ} \\
& B_{n c}=A_{n}(\theta, T) \cos \phi \text { for Compton }
\end{aligned}
$$

The polarization we measure for the mlxture of Compton and ${ }^{\circ}$ events is given by equation (2):

$$
P_{m}=\frac{\sum B_{n c}+\sum B_{n \pi}}{\sum B_{n c}^{2}+\sum B_{n \pi}^{2}}
$$

We can assume that the average andyzing power for the Compton events Is equal to that for the $\pi^{\circ}$ events:

$$
\frac{\sum B_{n c}^{2}}{\sum B_{n \pi}^{2}}=\frac{n c}{n \pi}
$$

using (5) and (4) we get:

$$
\begin{aligned}
P_{m} & =\frac{\sum B_{n c}}{\sum B_{n c}^{2}\left(1+\frac{n \pi}{n c}\right)}+\frac{\sum B_{n \pi}}{\sum B_{n \pi}^{2}\left(1+\frac{n \pi}{n c}\right)} \\
& =P c f c+P_{\pi}(1-f c) \text { with } f c=\frac{n c}{n c+n \pi} \\
P_{C} & =\frac{1}{f c}\left[P_{m}-(1-f c) P_{\pi}\right]
\end{aligned}
$$


The error in $\mathrm{PC}$ is dominated by the error in $\mathrm{P}_{m} . P_{\pi}$ is calculated from our ${ }^{\circ}$ events. fo is found by examining the coplanarity condition for Compton events as shown in Figure 5 . From the ${ }^{\circ}$ distribution away from the Compton peak we calculate the number expected under the Compton peak. The result is given in the following table:

\begin{tabular}{|c|c|c|c|}
\hline${ }_{p}(\mathrm{MeV})$ & $f \in(\$)$ & $T_{p}(M \rho V)$ & $f c(x)$ \\
\hline 120 & 20 & 220 & 15 \\
\hline 140 & 19 & 240 & 14 \\
\hline 160 & 17 & 260 & 14 \\
\hline 180 & 16 & 280 & 13 \\
\hline 200 & 15 & & \\
\hline
\end{tabular}

\section{Analyzlng Power}

Since we can only measure an asymetry directiy, and not the polartzation, we need to know the analyzing power for proton carbon scatters. We have taken the analyzing power from the compliation of McNeely. Figure 7 gives the analyzing power as a function of angle and energy. If write the probability distribution of scattered protons as $1+$ AP, where $P$ is the polarization, then the analyzing power is $A=A_{i}(\theta,+)$ cos $\phi$. The index refers to the $t^{\text {th }}$ inelastic fevel of proton carbon scattering. Our measurement of the energy loss in proton carbon scattering is not sutficiently accurate to sepsrate elastic scatters from some inelastlc scatters. For this reason we write the analyzing power as follows: 

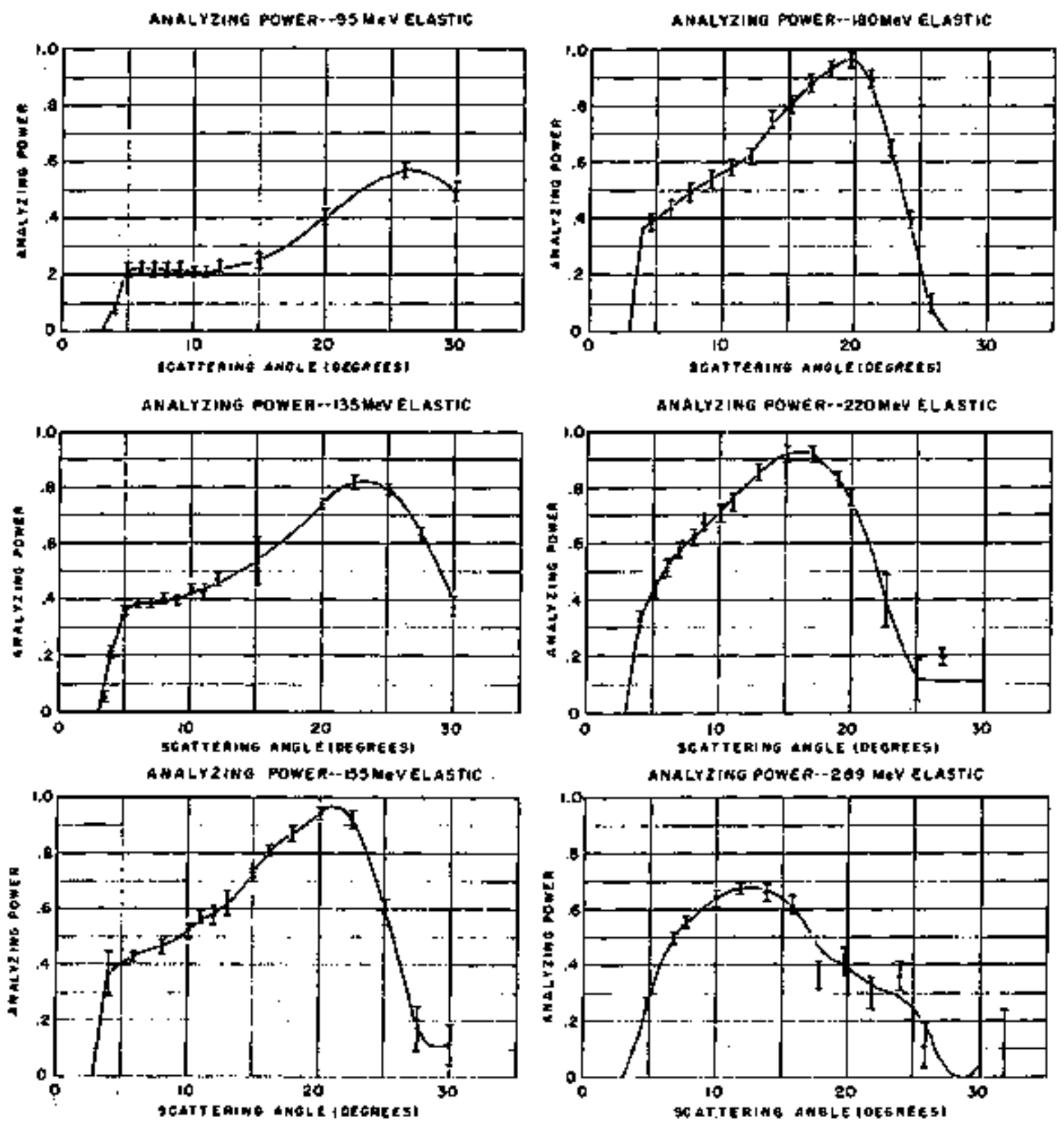

PROTON-CARBON ANALYZING POWER FROM:

ME NEEIY CTSL INTERNAL. REPORT " 30 GALT-68-113

FIGURE 7. ELASTIC PROTON-CARBON ANALYTING POWER. 


$$
\begin{aligned}
A & =\frac{\sum \sigma_{1}(T, \theta) w_{i}(\Delta T, \Gamma) A_{i}(T, \theta)}{\Sigma \sigma_{i}(T, \theta) w_{i}(\Delta T, \Gamma)} \\
w_{i}(\Delta T, \sigma) & =\exp \left[-\frac{\left(\Delta T-E_{i}\right)^{2}}{2 T^{2}}\right]
\end{aligned}
$$

The sum is over elastic and inelastic levels of proton carbon scattering. $\sigma_{i}$ and $A_{i}$ are the cross sections and analyzing powers. $\Gamma$ is the experimental energy resolution. Figure 8 is a graph of the energy loss distribution for scattered and unscattered protons. We cut $\Delta T$, the measured energy los5, at $20 \mathrm{MeV}$ to eliminate as many inelastics as possible. To further minimize the number of inelastic events we have chosen an upper cut off on the scattering angle of $\sqrt{T_{p} / 110} \cdot 25^{\circ}$. With these cuts the correction given above amounts to an average decrease in the analyzing power of $8 \%$. At small scatter angles the possibility arises that the analyzing power is diluted by Coulomb scatters. The width of the Coulamb peak varies between $1.6^{\circ}$ at our lowest energies to $0.8^{\circ}$ at the highest energies. We have set corresponding limits on the smallest acceptoble angle. It varies between $6^{\circ}$ and $4^{\circ}$ depending on the energy at the scatter. The angular distribution for two energies is shown in flgure 9.

A good measure of how well we can measure the polarization is given by the effoctive analyzing power defined by:

$$
\left.A_{e f f}=\underset{n}{[\Sigma} A(\theta, T)^{2} \cos ^{2} \phi / N\right]^{\frac{1}{2}}
$$



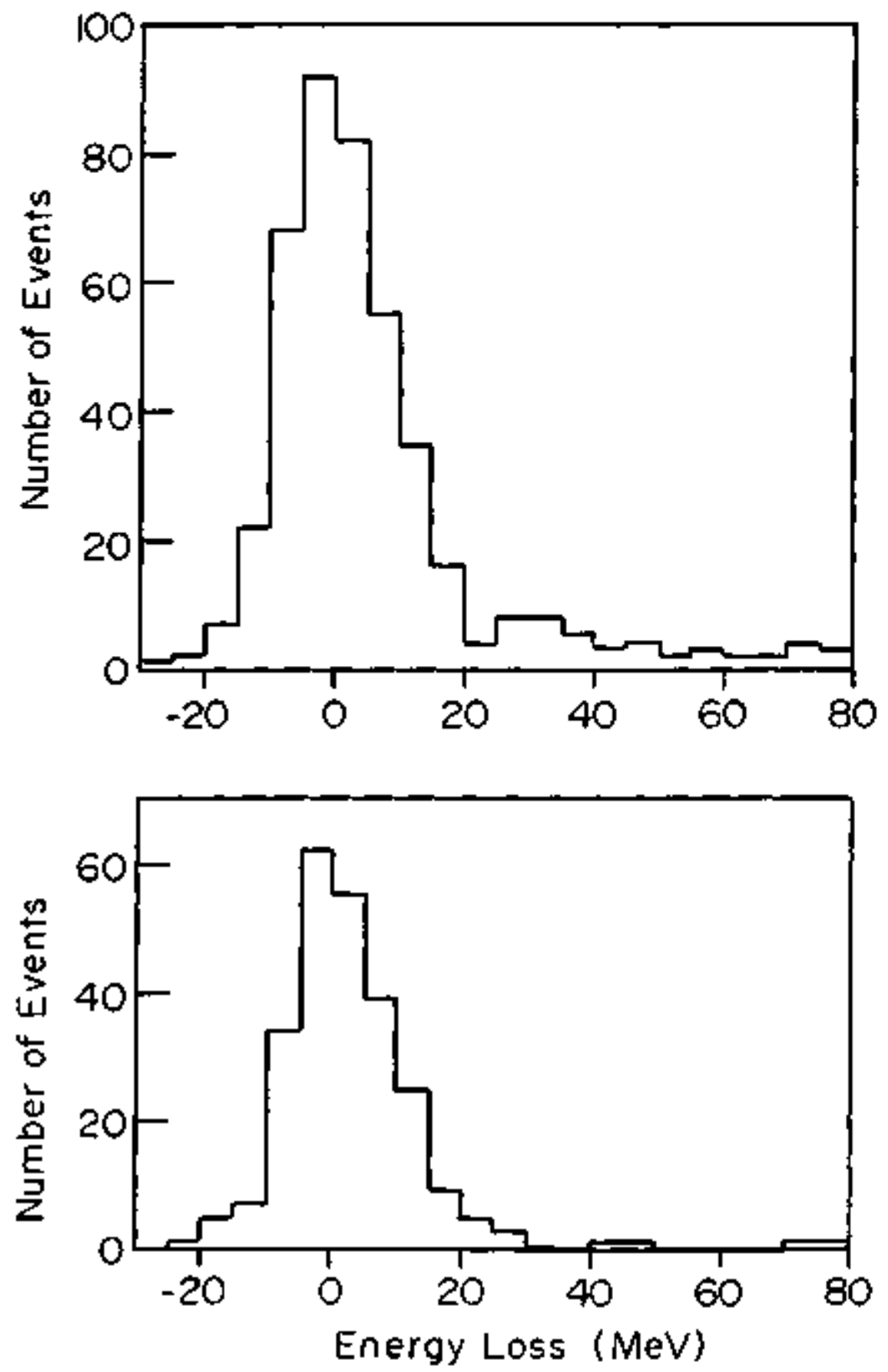

F GGURE 8. MEASUREO ENERGY LOSS FOR PROTONS IN THE REACTION $\gamma+p+\gamma+p$. TOP GRAPH IS FOR SCATTEREO PROTONS. BOTTON GRAPH IS FOR UNSCATTEREO PROTONS. 

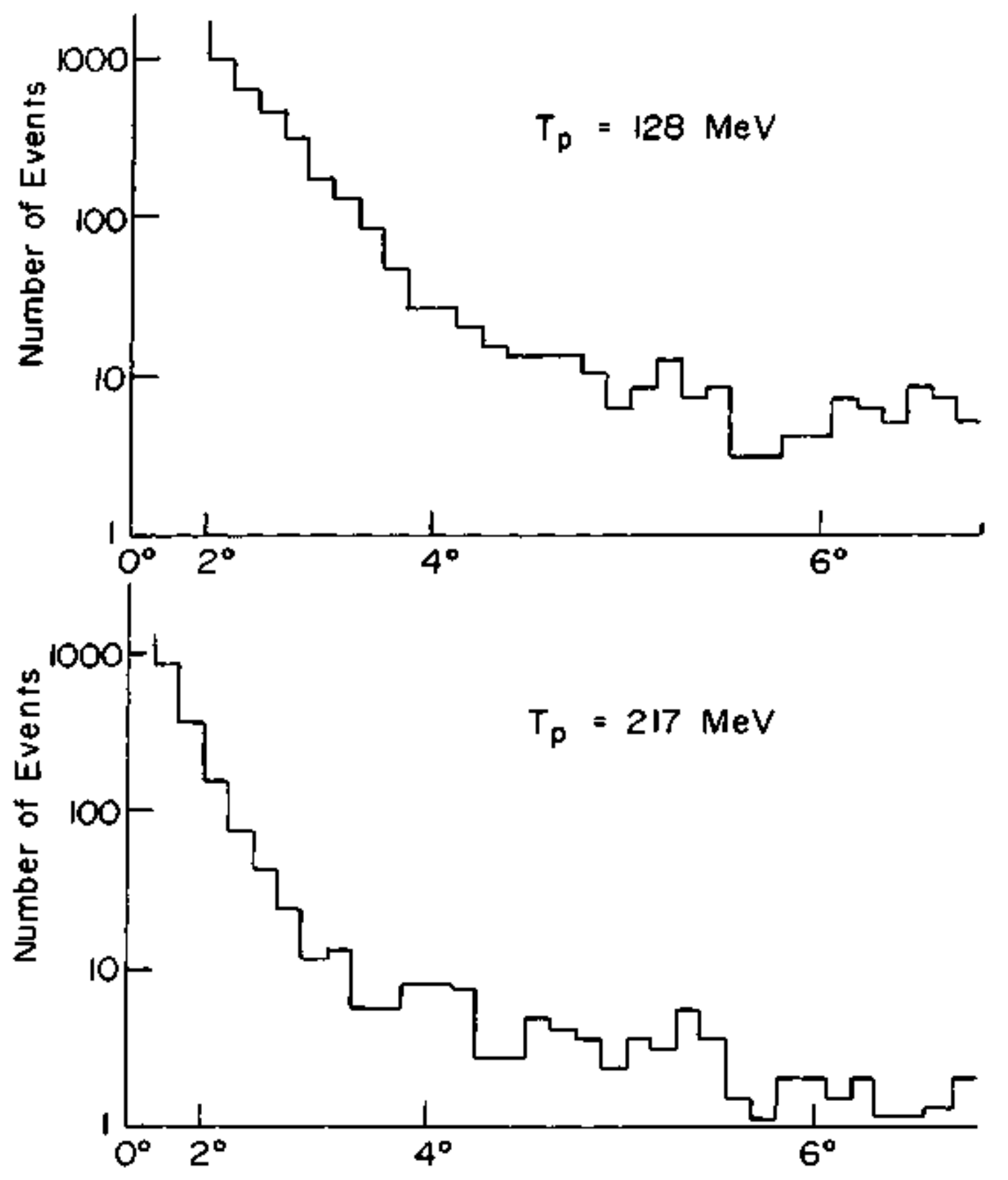

FIGURE 9. ANGULAR DISTRIEUTION FOR PROTON SCATTERS AT TWO DIFFERENT ENERGIES. 
The polarization is inversely proportional to $A_{\text {eff }}$ and the error is given by $1 /\left(\sqrt{\mathrm{N}} \mathrm{A}_{\text {eff }}\right)$. The effectlve analyzing power for our experiment is given in the table below. Note that the $\cos ^{2} \phi$ term contributes a factor of 0.72 on the average.

\begin{tabular}{|c|c|c|c|}
\hline$T_{p}(\mathrm{MeV})$ & Aeft & $T_{D}(\mathrm{MeV})$ & Aeft \\
\hline 120 & .24 & 240 & .40 \\
\hline 140 & .27 & 260 & .44 \\
\hline 160 & .31 & 280 & .45 \\
\hline 180 & .33 & 300 & .40 \\
\hline 200 &, 34 & 320 & .34 \\
\hline 220 & .35 & 340 & .31 \\
\hline
\end{tabular}

\section{Asymmetriess}

Checking that there are no asymmetries in our apparatus is a crucial part of our experiment.while most asymmetries have a negligible effect on our result, there is one source of asymmetry for which we have to apply a correction. It is caused by the fact that we requlre at least four sparks after the scatter point to accept an event. This requirement causes no asymnetry if the proton is incldent perpendicular to the carbon plates of the analyzer. However, if the proton enters the analyzer at an angle, then there can be an asymetry. The four sparks criterion requires that the range $R$ of the proton after the scatter is greater than some minimum $R_{0} / \cos \theta$. This requirement translates into different minimum ranges for left and right scatters: 


$$
R>\frac{R_{o}}{\cos \left(\theta_{p} \pm \theta_{s}\right)}
$$

$V !-6$

$\theta_{\rho}$ is the angle of the proton before the scatter; $\theta_{5}$ is the scatter angle. For a proton with given total energy scattering in a given carbon olate the requirement 6 may be satisfied if the scatter is to the right but not if the scatter is to the left. The asymmetry caused by this effect is given by the formula:

$$
\mathrm{S}=\frac{\mathrm{R}_{\mathrm{O}} / \cos \theta_{\mathrm{S}}}{\mathrm{R}_{\mathrm{g}} / \cos \theta_{\mathrm{s}}} \tan \theta_{\mathrm{s}} \tan \theta_{\mathrm{p}} \cos \phi_{\mathrm{s}} \quad \text { VI-7 }
$$

$R$ is the range after the scatter. We have catculated the polarization caused by this asymmetry. He take our scattered events and calculate:

$$
P=\sum_{n} S_{n} A\left(\theta_{n}, T_{n}\right)
$$

$S_{n}$ is calculated according to equation 7 for a given event. Al( ${ }_{n} \cdot T_{n}$ ? is the analyzing power. We find that $p$ Is significant only for the lowest energy bin. It amounts to $P=.175$ for Compton events and $P=.145$ for $\pi^{\circ}$ events. Note that this rather large polarization is coused by the very small angle $\theta_{p}=3^{\circ}$.

One possible source of asymmetry is that for some scatter angle tracks with scatters to one side may leave the chamber and be lost, while scatters to the other side may not. To remove this source of asymmetry we construct for each scatter to the left a track corresponding to a scatter to the right and vice versa. If either track falls outside a set fiducial volume, the event is rejected. 
A loss of events during track identification can concelvably be asymmetric. Since the two stereo views are independent we can examine sil events with disagreements between the two views. By thts means we find that $3.5 \%$ of the good scatters are lost. Most of these are subsequently recovered by manual intervention. There is no indication that for the few remaining events losses are more likely to occur for scatters to one side as opposed to scotters to the other side.

As mentioned in section IV $C$ the alignment of the proton chambers is of critical importance. A misalignment of one milliradian shifts the polarization by .017. We have checked our angle measurenent by finding the average profected angle in the Coulomb scatter reglon. The average is typically $\neq 1$ milliradian. Hence the error from this source is small compared to our statistical error.

As a final check we take kinenatically rejected events and measure their polartzation. We include production inelastles and inelastic proton scatters. The result is given in Figure 10. In the top graph $t$ is calculated from the proton range. For a glven the residual range and scatter gap distribution is the same as for the good events. However, the proton angular distribution is different. In the bottom graph $t$ is calculated from angles and the photon energy. Here the proton angular distribution is the same as for the good events; the residual range and scatter gap distribution is different. The average over all + is $-.07 \pm .05$. 


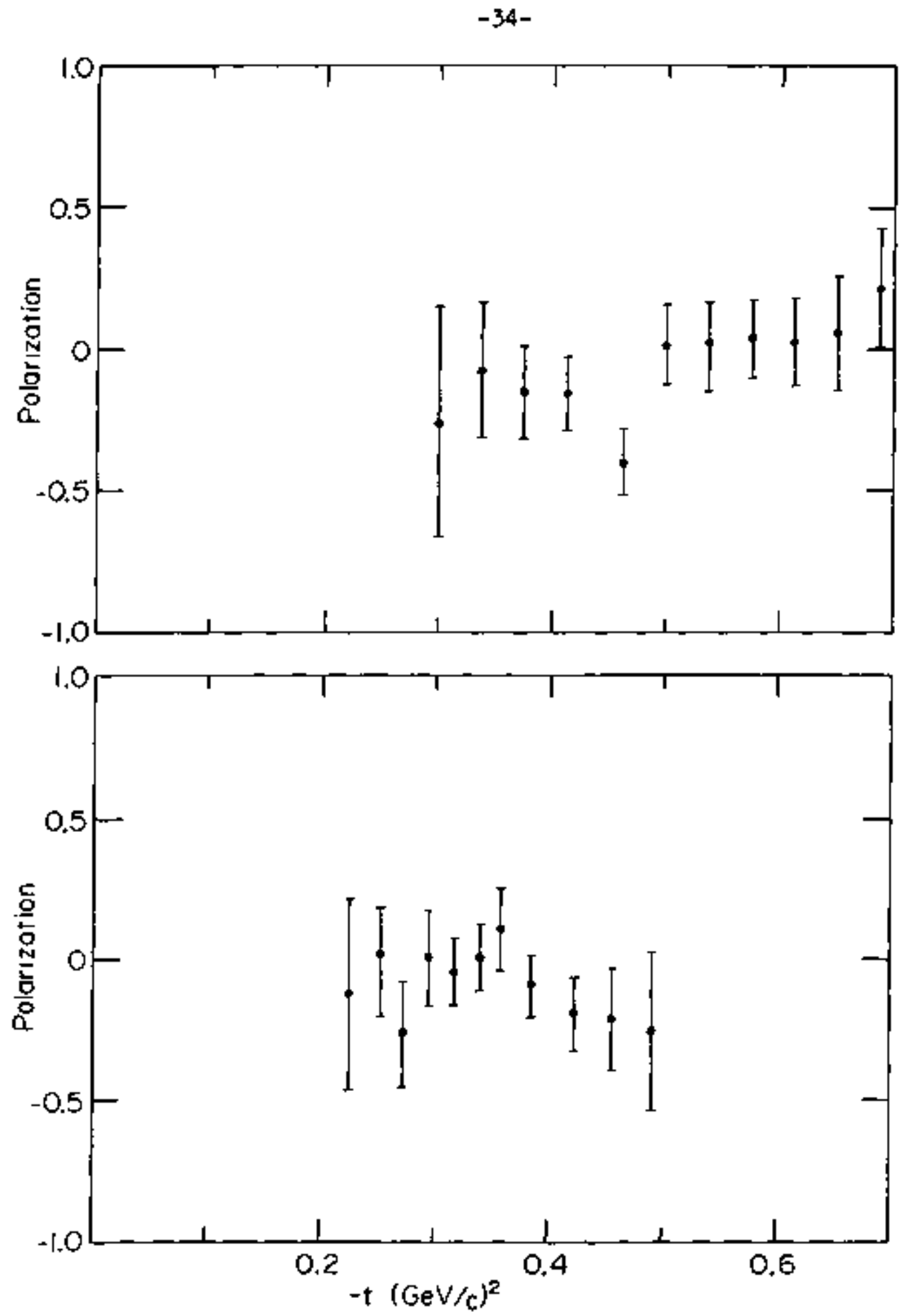

FIGURE 10. MEASUREO POLARIZATION FOR EYENTS REJECTEO FOR KINENAT IC REASONS. IN THE TOP GRAPH + IS CALCULATEO FROM ANGLES AND THE SHOWER ENERGY; IN THE BOTTOM GRAPH + IS CALCULATED FROM THE RANGE. 


\section{RESULTS}

Our result for the polarization of the recoil proton in $Y+p \rightarrow \pi^{0}+p$ is shown in Figure II. The direction of positive polarization is detined by $\hat{K} \times \hat{q}$, where $\hat{k}$ is the direction of the incldent phaton and $\hat{q}$ is the direction of the $\pi^{0}$. For comparlson we show the values for the target asymmetry.

As is evident from Figure 11 , the target asymmetry and polarization do not agree very well. We have tried to fit o simple polynomlal to both sets of data slmultaneously. Our flt produces a confidence level of less than $10^{-4}$. The conclusion one must draw is that the target aswmetry differs from the polarization.

There are two explanations for the discrepancy we observe. The most obvious is that there are unknawn systemetic errors. A further possibility arises from the fact that the experiments were done at different photon energies. Our photon energy extends from $3 \mathrm{GeV}$ to $7 \mathrm{GeV}$ with an average photon energy correlated wlth the momentum transfer as follows:

$$
K(\mathrm{HeV})=2900+5330(-+)(\mathrm{GeV} / \mathrm{c})^{2}
$$

The target asyminetry experiment was done with an endpoint energy of 4 Gev. Although one does not expect any variation with energy at these hlgh energies, we have no way of estimating how large such effects could by. The hypothesis $A_{p} \neq P$, while not Impossible, is rather uncomfortable from a theoretical point of view. It means that the two helicity nonflip amplitudes $g_{2}$ and $g_{3}$ are unequal. 

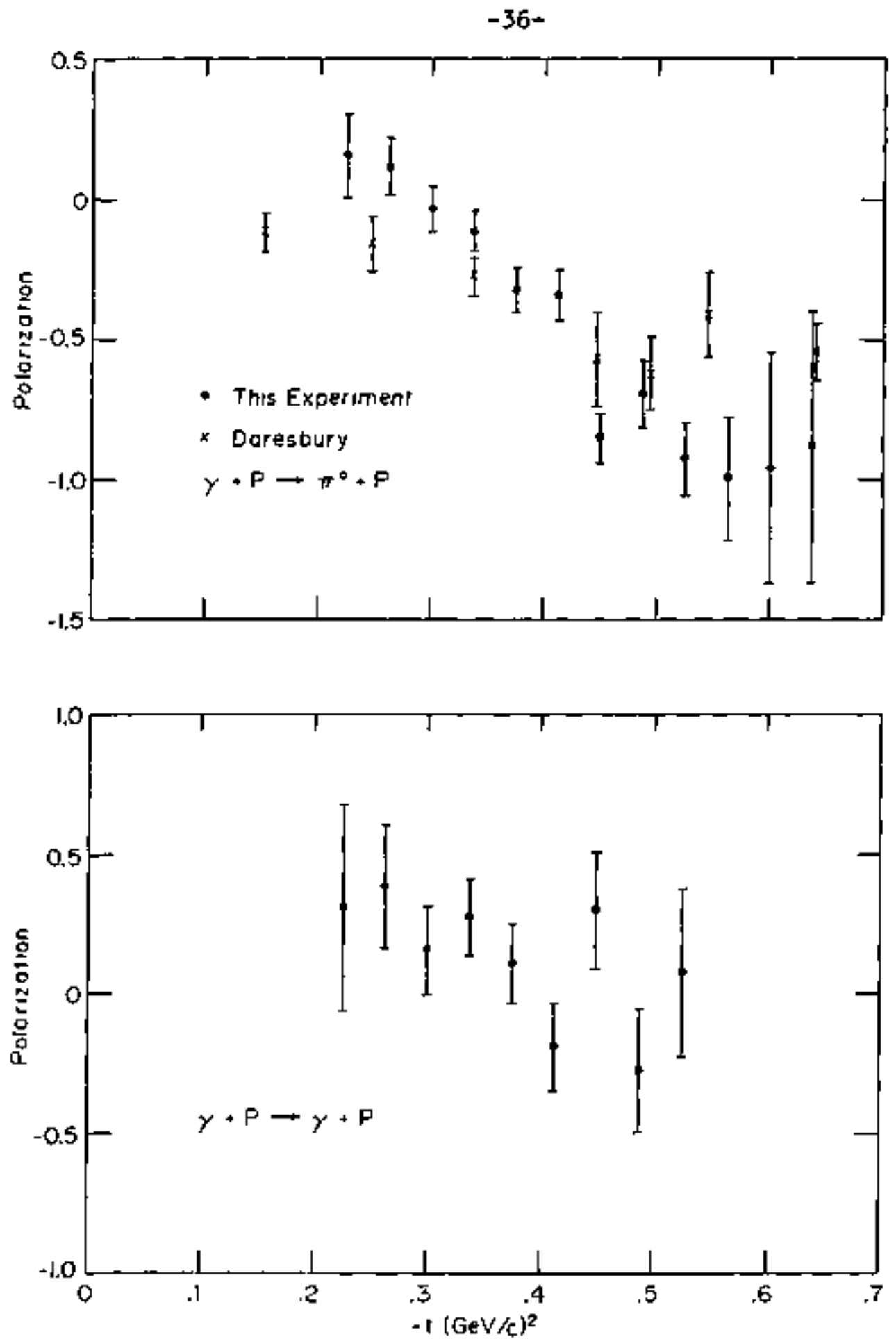

FIGURE 11. PDLARITATION OF THE RECOIL FROTON. TOP GRAPH IS FOR $Y+p \rightarrow \pi^{\circ}+\rho$ : BOTTOM GRAPH IS FOR $\gamma+p \rightarrow r^{0}+p$. IARGET ASYMMETRY RESULT IS SHOWN FOR COMPARISON. 
We have also tried to fit smooth curves to the target asymetry

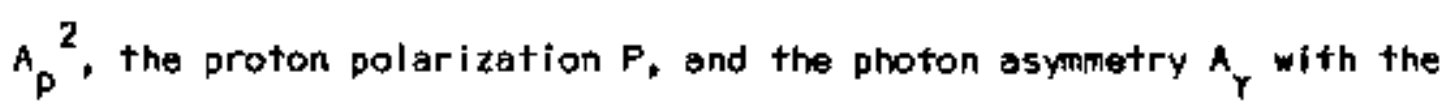
constraint $\left|A_{p}-P\right|<I-A_{\gamma}$. We find a confidence level of about 0.25 for $A_{Y}$. We hove used only the SLAC data. ${ }^{9}$ We see no reason to believe that the data violate the above constraint. However, from the fact that $\left|A_{D}-P\right|<1-A_{Y}$ is barely satistied, we get a further result. Using equations $11-2$ and $11-3$ we have:

$$
\begin{aligned}
& \left|g_{2}-g_{3}\right|=\left|g_{4}-g_{1}\right| \\
& \phi_{2}-\phi_{3}=\phi_{4}-\phi_{1}+\theta
\end{aligned}
$$$$
\theta=\frac{\pi}{2} \text { or } \frac{3 \pi}{2}
$$

$\phi_{i}$ Is the phase of the amplitudes $9_{i}$.

Our Compton result is also shown in Figure 11. There is no significant structure in the polarizatlon. The average is .12 \pm .06 . Using equation 11-6 we can put 3 limit an the ratio of the hellcityflip amplitude to the helictty-nonflip amplitude:

$$
\frac{2 \text { Ret } 2}{\left(f_{1}{ }^{2}+t_{3}\right)^{\frac{1}{2}}}+.12 \pm .06
$$




\section{REFERENCEES}

1. R.L. Anderson et al., Phys. Rev. Letters 26, 30 (1971) D. Bellenger et al, Phys. Rev. Letters 23, 540 (1969)

2. P.S.L. Booth et ai., Phys. Letters 38B. 339 (1972).

3. J.D. Jackson and C. Quigg, Nucl. Phys. B22, 30t (1970).

4. F.D. Gault et al., Nucl. Phys. B32. 427 (1971).

5. R. Worden, Nucl, Phys. [337. 253 (1972).

6. L. Golub, Thests, M. 1.T. (1972).

7. D. Potter, Thesis, M.1.T. (1972).

8. W.A. McMeely, CTSL Internal Report $\$ 30$ (1967).

9. R.L. Anderson et 81., SLAC Pub. 925 (1971) 


\section{ACKNOWLEDGEMENTS}

We are indebted to the crew at the Canbrldge Electron Accelerator for alding us in the performence of preliminary experiments. Our thanks to the staff of the Cornell Wilson Laboratory for their kind hospltality ond efficlent assistance In the execution of this experlment. To Mike Shupe, Bob Digrazia, and David Osborne we wish to express our oppreciation for helping us in the preparation of this experiment. 